\title{
La práctica colectiva de la música. Banda Sinfónica Juvenil de San Pedro Sula: Espacio posible para el desarrollo social sostenible
}

\author{
The Collective Practice of Music. Youth Symphonic Band of San Pedro Sula: A Possible Space \\ for Sustainable Social Development
}

\section{A prática coletiva da Música. Banda Sinfônica Jovem de São Pedro Sula: Um espaço possível para o desenvolvimento social sustentável}

\author{
Oswaldo Antonio Rodríguez-Reinoso \\ Universidad Tecnológica Centroamericana \\ Centro Universitario Tecnológico \\ San Pedro Sula, Honduras \\ Josemanuel Luna-Nemecio \\ Centro Universitario CIFE \\ Cuernavaca, México \\ josmaluna2@gmail.com \\ https://orcid.org/0000-0002-6850-3443
}

Recibido • Received • Recebido: 25 / 02 / 2020

Corregido • Revised • Revisado: 19 / 08 / 2021

Aceptado • Accepted • Aprovado: 02 / 11 / 2021

\section{Resumen:}

Introducción. La educación musical que combina propósitos de orden disciplinar y de desarrollo social representa una alternativa que redimensiona la enseñanza-aprendizaje de la música a partir de un hacer colectivo. La Banda Sinfónica Juvenil de San Pedro Sula (BSJ-SPS) es un programa de educación musical, no formal, que vivencia la práctica colectiva de la música como espacio para el desarrollo social sostenible. Propósitos. Develar los aspectos pedagógicos, artísticos y socioculturales de dicha experiencia a luz de los planteamientos en torno a la educación musical con fines desarrollo social. Metodología. La investigación de enfoque cualitativo, cuasiexperimental y de carácter descriptiva empleó la narrativa testimonial de ocho estudiantes de la BSJ-SPS recogida en entrevistas semiestructuradas, analizadas mediante técnica de categorización y codificación. Resultan del análisis doce categorías emergentes que enmarcan la experiencia de la BSJ-SPS desde la vivencia de sus estudiantes en lo pedagógico, lo artístico y lo sociocultural. Conclusiones. Se evidencia una clara vinculación entre propósitos disciplinares y de desarrollo social en el programa BSJ-SPS. Sus integrantes vivencian una práctica a la que reconocen como factor de importante transformación personal afianzando su proyecto ético de vida.

Palabras claves: Educación musical; desarrollo social sostenible; socioformación; competencias. 
http://doi.org/10.15359/ree.26-1.17

http://www.una.ac.cr/educare

educare@una.ac.cr

\begin{abstract}
:
Introduction. Music education, which combines disciplinary and social development purposes, represents an alternative that re-dimensions the teaching-learning of music from a collective doing. The Youth Symphonic Band of San Pedro Sula (BSJ-SPS) is a non-formal musical education program that experiences the collective practice of music as a space for sustainable social development. Purposes. To reveal the pedagogical, artistic, and socio-cultural aspects of this experience in the light of approaches to music education for social development. Method. The qualitative, quasiexperimental, and descriptive research used the testimonial narrative of eight (8) students of the BSJSPS collected in semi-structured interviews, analyzed through categorization and coding techniques. The analysis resulted in twelve emerging categories that frame the experience in the BSJ from the experience of its students, both pedagogically and artistically and socio-culturally. Conclusion. There is a clear link between disciplinary and social development purposes in the BSJ program. Its members experience a practice that they recognize as a factor of important personal transformation, strengthening their ethical life project.
\end{abstract}

Keywords: Music education; sustainable social development; socioformation; skills.

\begin{abstract}
Resumo:
Introdução. A educação musical, que combina fins disciplinares e de desenvolvimento social, representa uma alternativa que redimensiona o ensino-aprendizagem da música a partir de um fazer coletivo. A Banda Sinfônica Jovem de São Pedro Sula (BSJ-SPS) é um programa de educação musical não formal que experimenta a prática coletiva da música como espaço para o desenvolvimento social sustentável. Objetivo. Revelar os aspectos pedagógicos, artísticos e socioculturais desta experiência à luz das abordagens da educação musical para o desenvolvimento social. Metodologia. A pesquisa qualitativa, quase-experimental e descritiva utilizou as narrativas testemunhais de oito estudantes de BSJ-SPS coletadas em entrevistas semiestruturadas, analisadas por meio de uma técnica de categorização e codificação. A análise resultou em doze categorias emergentes que enquadram a experiência no BSJ a partir da experiência de seus estudantes tanto pedagógica como artística e sociocultural. Conclusão. Há uma clara ligação entre os objetivos disciplinares e de desenvolvimento social no programa BSJ. Seus membros experimentam uma prática que reconhecem como um fator de importante transformação pessoal, fortalecendo seu projeto ético de vida.
\end{abstract}

Palavras-chave: Educação musical; desenvolvimento social sustentável; sócio formação; competências.

\title{
Introducción
}

Han sido exploradas las posibilidades de articular aspectos ontoepistémicos y metodológicos que relacionan educación musical y desarrollo social sostenible (Rodríguez, 2019; Rodríguez-Reinoso y Luna-Nemecio, 2019) como alternativa de cambio desde la socioformación (López-Vázquez y Veytia-Bucheli, 2019). Vincular desarrollo social sostenible (Luna-Nemecio, 2020) y educación musical, trae consigo la exigencia a esta última de una amplitud nocional y conceptual mayor, puesto que no solo se persiguen metas relacionadas con las destrezas instrumentales, el domino de la lecto-escritura, principalmente, sino que 
http://doi.org/10.15359/ree.26-1.17

el proceso de enseñanza-aprendizaje musical busca la realización plena e integral del sujeto participante y, más aún, cuando este se encuentra en condiciones socioculturales desfavorables. Así, la práctica musical se constituye como medio y fin.

El referente más importante, en tanto mediación político-educativa más conocido a este respecto es El Sistema, nombre con el que se ha conocido mundialmente la iniciativa del músico venezolano José Antonio Abreu (1933-2018) fundador de todo un proyecto a escala nacional en Venezuela que le ha valido tanto el reconocimiento como las críticas (Baker, 2018) al planteamiento de una acción social por la música desde el 1975, hoy en la figura de la Fundación Musical Simón Bolívar, órgano rector del Sistema Nacional de Orquestas y Coros Juveniles e Infantiles de Venezuela (Erhlin y Gustavsson, 2018; Roué, 2017; Verhagen et al., 2016; Wald, 2017).

El planteamiento de una educación musical como acción social fue tomando forma a partir de la vinculación con las mediaciones políticas del Estado venezolano (Salas Rivera, 2018), con el apoyo de cuantiosos recursos provenientes, principalmente, de organismos multilaterales como el Banco Interamericano de Desarrollo -BID- (Alemán et al., 2016) que permiten la asignación de instrumentos de manera gratuita, el pago de docentes, la construcción de sedes para el desarrollo de la política educativa y un conjunto de actividades de orden académicoartísticas dentro y fuera de Venezuela.

Iniciativas como las del modelo venezolano no son las únicas que se atribuyen la idea de vincular la práctica musical con propósitos de orden social. En Latinoamérica hay que referir el trabajo de Jorge Peña Hen en Chile "cuyo legado cultural y social convirtió a La Serena en cuna de las orquestas infantiles y juveniles en América Latina" posibilitando a posteriori el desarrollo de la experiencia venezolana (Escribal, 2017, p. 116).

En este sentido, el presente artículo aborda la experiencia de una institución hondureña que se ha planteado el reto de asumir la educación musical conjuntamente con el desarrollo social. Se trata de la Banda Sinfónica Juvenil de San Pedro Sula (BSJ-SPS), creada en el año 2008 por un grupo de docentes quienes se propusieron establecer un movimiento de formación musical integrado, fundamentalmente, por jóvenes en condiciones socio-culturales desfavorables, sin posibilidades de acceso a la educación para las artes, con fuertes riesgos de ser atrapados por flagelos como la delincuencia, las drogas, la violencia callejera o la prostitución, problemas que han marcado negativamente a la sociedad hondureña.

\section{La práctica musical en colectivo y su implicación en lo social}

La práctica de la música a partir de una colectividad llamada orquesta, coro o banda viene a ser el centro de este planteamiento, el cual se contrapone a la visión del sujeto individual virtuoso del modelo conservatorio. En el documental/película Tocar y luchar (de Alberto Arvelo), José Antonio Abreu expresa: que "una orquesta es una comunidad" la cual se constituye con la 
http://doi.org/10.15359/ree.26-1.17

http://www.una.ac.cr/educare

educare@una.ac.cr

característica "esencial y exclusiva de concertarse", entendiendo por esto "la práctica del equipo, la práctica del grupo que se reconoce a sí mismo como interdependiente, donde cada uno es responsable por los demás y los demás son responsables por uno" (López, 2021, 11:04).

A partir de aquí se hacen concomitantes diversas aproximaciones entorno a una educación musical asumida desde el colectivo con finalidades compartidas, las de orden pedagógico-artístico y las de orden sociocultural-político, que requiere de un análisis epistémico y metodológico del proceso de enseñanza-aprendizaje musical como factor necesario del desarrollo social sostenible. Dicho análisis permitirá contextualizar, más que enmarcar o clasificar, las diferentes experiencias alternativas de educación musical que han surgido a partir del planteamiento de El Sistema.

La noción de Community Music (Comunidades Musicales), por ejemplo, en autores como Roué (2017) se establece como la base de proyectos educativos en Sudáfrica, a partir de los cambios políticos de finales de los años noventa que permitieron brindar atención a niños y niñas con grandes limitaciones sociales de acceso a la educación musical. Por su parte, el planteamiento de Hospital et al. (2018) de una educación musical basada en ensambles (Music Educationensemble-based) involucra una gama de habilidades tales como la auto-concienciación, auto-expresión, además que fortalece "la autorregulación a través del aprendizaje de la lectura y la ejecución de la música, y promueve la concientización social y la colaboración a través de la actuación en conjunto" (p.150).

De igual modo, al hablar de música comunitaria (D’Alexander e llari, 2016) es preciso identificar los puntos convergentes entre las prácticas que se inspiran en el modelo El Sistema como aquellas que no. Allí se destacan "características que incluyen un énfasis en las actividades musicales que enriquezcan la vida cultural de los participantes y la comunidad, los procesos y relaciones positivas maestro alumno, la conciencia de los individuos y grupos más desfavorecidos" (p. 76) lo mismo que el reconocimiento del crecimiento personal y social de las personas participantes. En la perspectiva de Ehrlin y Gustavsson (2018), la participación de un sujeto en una comunidad de prácticas; en este caso, prácticas musicales, puede entenderse a partir del cambio de ser una persona participante en el borde exterior de una comunidad a convertirse, con el tiempo, en una persona participante, o persona actora, cada vez más central, cuyo aprendizaje es posible mediante la interacción en dicha comunidad de prácticas.

\section{Propósitos}

En atención a lo anteriormente expuesto, el presente desarrollo investigativo establece como propósitos de estudios: 1) develar los aspectos significativos de orden pedagógico, artístico y socio-cultural presentes en la práctica educativo musical de la BSJ-SPS; 2) contrastar el marco epistemológico que sustenta las prácticas educativas-musicales en colectivo con la narrativa testimonial de informantes claves pertenecientes a la comunidad BSJ-SPS; 3) vincular la 
http://doi.org/10.15359/ree.26-1.17

http://www.una.ac.cr/educare educare@una.ac.cr

experiencia de la Banda Sinfónica Juvenil de San Pedro Sula al planteamiento de la socioformación y el desarrollo social sostenible y 4) ofrecer resultados que contribuyan a documentar las experiencias formativas de la BSJ-SPS en el contexto de la educación musical hondureña.

\section{Método y metodología}

\section{Tipo de estudio}

Se asume una investigación cualitativa entendida como aquella que "produce hallazgos a los que no se llega por medio de procedimientos estadísticos u otros medios de cuantificación" (Strauss y Corbin, 2002, pp.19-20). Con un diseño cuasi experimental, y de carácter descriptivo, se plantea un tipo de investigación que aborda "la vida de la gente, las experiencias vividas, los comportamientos, emociones y sentimientos, así como el funcionamiento organizacional, los movimientos sociales, los fenómenos culturales y la interacción entre las naciones" (Strauss y Corbin, 2002, p. 20). Así mismo, el enfoque cualitativo de la investigación lleva a considerar el paradigma interpretativo (Corbetta, 2007) y, con ello, la hermenéutica en tanto método, sobre la cual se levantará el proceder analítico de la información a recabar.

\section{Diseño de instrumento}

La técnica de recolección de la información será la entrevista de tipo semiestructurada en la que el sujeto entrevistador dispone de un guion con los temas que debe tratar en la entrevista (Corbetta, 2007) y, con ello, puede establecer la manera de tratar los temas y formular las preguntas. "La entrevista es la técnica por excelencia dentro de la investigación cualitativa, por medio de ella "se obtiene toda aquella información que no obtenemos con la observación, porque a través de ella podemos penetrar en el mundo interior del ser humano y conocer sus sentimientos, su estado anímico, sus ideas, sus creencias y conocimientos" (Cerda, 1993, pp. 258-259). La entrevista (ver Material Complementario) tendrá una composición en tres partes: a) aspectos socio-culturales (entorno personal, familiar, comunidad, escolar), b) aspectos pedagógicos-artísticos de la experiencia educativo musical y, c) expectativas futuras.

Fueron seleccionados para la realización de la entrevista, con la anuencia de la institución y de manera intencionada, ocho estudiantes pertenecientes al segundo, tercer y cuarto año de formación de la comunidad Banda Sinfónica Juvenil de San Pedro Sula de un total de 45 estudiantes que conforman la matrícula en el período académico-artístico 2019. Para el análisis de la información obtenida de la narrativa testimonial se procedió siguiendo el método hermenéutico por medio de las técnicas de categorización y codificación. De acuerdo con Mejía Navarrete (2011), la información recabada por medio de la categorización "descompone o divide en unidades temáticas que expresan una idea relevante del objeto de estudio" (p. 51) y la codificación "asigna a cada unidad categorial una determinada notación, etiqueta o palabra que expresa el contenido conceptual" (Mejía Navarrete, 2011, p. 52). 
http://doi.org/10.15359/ree.26-1.17

http://www.una.ac.cr/educare

educare@una.ac.cr

\section{Hallazgos}

Estos se presentan mediante tablas resumen. La Tabla 1 presenta un resumen de la narrativa testimonial de los informantes en función de la experiencia personal como aspecto/ tema abordado con sus correspondientes ítems asignados para la entrevista.

Tabla 1: Narrativa testimonial a partir del aspecto/tema experiencia personal

\begin{tabular}{|c|c|c|}
\hline Aspecto/Tema & Ítem asignado & Narrativa testimonial \\
\hline \multirow{20}{*}{$\begin{array}{l}\text { Experiencia } \\
\text { personal }\end{array}$} & \multirow{5}{*}{$\begin{array}{l}\text { Motivación/ } \\
\text { Expectativas para } \\
\text { estudiar música }\end{array}$} & "Porque siempre había Ilamado la atención la música" \\
\hline & & $\begin{array}{l}\text { "Mis motivos fueron porque quería tener más conocimiento sobre el } \\
\text { instrumento". }\end{array}$ \\
\hline & & $\begin{array}{l}\text { "Mis motivos eran primeramente ejecutar el saxofón ser parte del grupo de } \\
\text { alabanza, ese fue mi primer motivo". }\end{array}$ \\
\hline & & $\begin{array}{l}\text { "Yo quería aprender a tocar un instrumento porque mis primos son } \\
\text { graduados de la Victoriano y quería saber qué se sentía". }\end{array}$ \\
\hline & & $\begin{array}{l}\text { Porque los vi tocar en un concierto de Navidad de Diunsa, y mi expectativa } \\
\text { es de seguir con la música". }\end{array}$ \\
\hline & \multirow{5}{*}{$\begin{array}{l}\text { Influencia de la } \\
\text { experiencia vivida }\end{array}$} & $\begin{array}{l}\text { "Ha cambiado mi vida por completo antes no tenía nada productivo que } \\
\text { hacer y desde que entré he explotado mi talento". }\end{array}$ \\
\hline & & $\begin{array}{l}\text { "Sin duda alguna, pienso que un cada uno de esos aspectos ha influido. Creo } \\
\text { que el aprender música, el estar frente a las personas me ha ayudado mucho } \\
\text { en mis relaciones, el mantenerme lejos de los problemas". }\end{array}$ \\
\hline & & $\begin{array}{l}\text { "Si, ha influido mucho, en lo personal me ha ayudado en poder ser valiente } \\
\text { de un modo, a ya no tener perna ante un público". }\end{array}$ \\
\hline & & $\begin{array}{l}\text { "Me ha ayudado a ser una mejor persona, una persona con responsabilidad } \\
\text { y con mucho orgullo me siento ser parte de esta institución. Me ha ayudado } \\
\text { en lo familiar también". }\end{array}$ \\
\hline & & $\begin{array}{l}\text { "Me ha enseñado a ser más responsable en mis cosas, tener más disciplina, } \\
\text { tener a mi familia que me apoya más". }\end{array}$ \\
\hline & \multirow{5}{*}{$\begin{array}{l}\text { Percepción del } \\
\text { grupo familiar/ } \\
\text { social cercano }\end{array}$} & "Mi familia está orgullosa de mi" \\
\hline & & "El programa que muestra la BSJ ha hecho un impacto grande en mi familia". \\
\hline & & "Se sienten orgullosos y el apoyo nunca falta de parte de ellos" \\
\hline & & "Se sienten orgullosos de verme en un escenario". \\
\hline & & "Muchos me apoyan y me dicen que siga así". \\
\hline & \multirow{5}{*}{$\begin{array}{l}\text { Aspiraciones } \\
\text { para futuro }\end{array}$} & "Pues llegar a ser una buena flautista". \\
\hline & & "Ir a la Orquesta Filarmónica de Seúl". \\
\hline & & "Pues desearía dedicarme al cien por ciento (100\%) a la música". \\
\hline & & "Lo primero sería graduarme de la BSJ y tener el título de maestro en el instrumento". \\
\hline & & $\begin{array}{l}\text { "Mejorar en mi instrumento, como persona. Tal vez, en el futuro dedicarme a } \\
\text { la música". }\end{array}$ \\
\hline
\end{tabular}

Nota: Elaborada por los autores. 
http://doi.org/10.15359/ree.26-1.17

http://www.una.ac.cr/educare educare@una.ac.cr

La Tabla 2 presenta un resumen de la narrativa testimonial de las personas informantes en función de la Experiencia Pedagógica-Didáctica como aspecto/tema abordado con sus correspondientes ítems asignados en la entrevista.

Tabla 2: Narrativa testimonial a partir del aspecto o tema Experiencia Pedagógica-Didáctica

\begin{tabular}{|c|c|c|}
\hline Aspecto/Tema & Ítem asignado & Narrativa testimonial \\
\hline \multirow{18}{*}{$\begin{array}{l}\text { Experiencia } \\
\text { pedagógica-didáctica }\end{array}$} & \multirow{6}{*}{$\begin{array}{l}\text { Experiencia en el programa } \\
\text { de formación BSJ }\end{array}$} & $\begin{array}{l}\text { "Pues ha sido divertido, y he aprendido mucho en la parte práctica como } \\
\text { teórica". }\end{array}$ \\
\hline & & $\begin{array}{l}\text { "Bien, porque me he divertido y he aprendido mucho en estos años y me } \\
\text { he esforzado por estudiar". }\end{array}$ \\
\hline & & "Muy buena y divertida, he hecho muchas amistades valiosas para mí". \\
\hline & & $\begin{array}{l}\text { "Pues ha sido muy satisfactorio y me realizado cosas que nunca me creí } \\
\text { capaz de hacer". }\end{array}$ \\
\hline & & $\begin{array}{l}\text { "Ha sido una experiencia significativa para mí. Creo que la música me } \\
\text { ayuda a mejorar, he aprendido mucho, creo que se descubren cosas que } \\
\text { tal vez pensábamos que no eran para nosotros. }\end{array}$ \\
\hline & & $\begin{array}{l}\text { "Que en la Música se vive todo, se siente, aprendemos a ser más unidos, } \\
\text { compartir experiencia con mis otros compañeros". }\end{array}$ \\
\hline & \multirow{6}{*}{$\begin{array}{l}\text { Aspectos significativos del } \\
\text { programa de formación }\end{array}$} & “Enseñar música y hacer que los estudiantes logren llegar más alto". \\
\hline & & "Que el estudiante aprenda música y que aprenda a ejecutar el instrumento". \\
\hline & & $\begin{array}{l}\text { "A enseñarnos a ser buenos músicos, a poder ser mejores en la técnica } \\
\text { con nuestro instrumento". }\end{array}$ \\
\hline & & $\begin{array}{l}\text { "Pero más importante nos enseñan valores, a ser responsables, } \\
\text { respetuosos, puntales, honestos, a que siempre sin importar nada } \\
\text { recordar nuestros orígenes y respetarlos estar orgullosos de ellos". }\end{array}$ \\
\hline & & $\begin{array}{l}\text { "Nos enseñan a tener un rol importante en nuestras filas y no pensar que } \\
\text { somos menos que los demás A tener responsabilidad por cada uno de } \\
\text { nosotros, que cuidemos el medio ambiente". }\end{array}$ \\
\hline & & $\begin{array}{l}\text { "Que cuidemos el medio ambiente, integridad, respeto, puntualidad, } \\
\text { responsabilidad, ayudarnos a otros". }\end{array}$ \\
\hline & \multirow{6}{*}{$\begin{array}{l}\text { Relación social docente- } \\
\text { estudiante y metodología }\end{array}$} & "Que es buena y unida, el contenido lo enseñan de una manera buena". \\
\hline & & $\begin{array}{l}\text { "Es una metodología que nos lleva a un estudio individual y a veces a } \\
\text { partes seccionales". }\end{array}$ \\
\hline & & $\begin{array}{l}\text { "El trabajo de los docentes me parece excelente, creo que la metodología } \\
\text { y el aprendizaje están muy bien". }\end{array}$ \\
\hline & & "Considero al maestro A el más enfocado en transmitir sus conocimientos". \\
\hline & & $\begin{array}{l}\text { "Mi maestro C que me ayudó con las escalas, los ejercicios, su método de } \\
\text { enseñar es muy bueno". }\end{array}$ \\
\hline & & "Muchas veces tenemos que pedirle ayuda al Profe A o al Profe B". \\
\hline
\end{tabular}

Nota: Elaborada por los autores. 
http://doi.org/10.15359/ree.26-1.17

http://www.una.ac.cr/educare

educare@una.ac.cr

La Tabla 3 presenta un resumen de la narrativa testimonial de las personas informantes en función de la experiencia artística como aspecto/tema abordado con sus correspondientes ítems asignados para la entrevista.

Tabla 3: Narrativa testimonial a partir del aspecto/tema experiencia artística

\begin{tabular}{|c|c|c|}
\hline Aspecto/Tema & Ítem asignado & Narrativa testimonial \\
\hline \multirow{5}{*}{$\begin{array}{l}\text { Experiencia } \\
\text { artística }\end{array}$} & \multirow{5}{*}{$\begin{array}{l}\text { Vivencia en el } \\
\text { escenario }\end{array}$} & "Ha sido entretenido y una opción de aprendizaje". \\
\hline & & $\begin{array}{l}\text { "Mi experiencia la describo como muy buena, el tocar y poder demostrar mi } \\
\text { talento es muy satisfactorio y me alienta a seguir en la BSJ" }\end{array}$ \\
\hline & & $\begin{array}{l}\text { "Al tocar en los escenarios siento que expreso con el instrumento lo que no se } \\
\text { puede expresar con palabras". }\end{array}$ \\
\hline & & $\begin{array}{l}\text { "Es una experiencia que te llena de adrenalina, los pelos de punta, nervios de } \\
\text { acero, y pensar cada segundo de lo que haces, sabiendo que te encanta y te } \\
\text { llena de emoción y más amor hacia la música". }\end{array}$ \\
\hline & & $\begin{array}{l}\text { "Pues me siento con mucha alegría por llegar a donde estoy porque sé que } \\
\text { he llegado a lejos. Siento la música cuando la ejecuto y no decir no puedo } \\
\text { hacerlo, no puedo tocarlo se ha significado mucho para mí". }\end{array}$ \\
\hline
\end{tabular}

Fuente: Elaborada por los autores.

Tabla 4: Categorías emergentes desde el análisis de la narrativa testimonial

\begin{tabular}{ll}
\hline \multicolumn{1}{c}{ Aspecto investigado } & \multicolumn{1}{c}{ Categorías emergentes } \\
\hline Experiencia personal & - Voluntad personal \\
& - Motivación social \\
& - Afirmación positiva de la experiencia vivida \\
& - Acompañamiento familiar \\
& - Perspectiva del proyecto ético de vida \\
\hline Experiencia pedagógica-didáctica & - Énfasis en el aprendizaje y goce personal \\
& - Vivencia integral/holística \\
& - Propósitos disciplinares \\
& - Aceptación de la metodología-contenido \\
& - Reconocimiento del rol docente \\
\hline Experiencia artística & - Sentido de autorrealización \\
\hline
\end{tabular}

Nota: Elaborada de los autores. 


\section{Discusión}

A partir de las categorías emergentes es posible observar que el programa BSJ-SPS es reconocido por el estudiantado encuestado como un espacio en donde se convive plenamente desde la práctica instrumental en colectivo, adquiriendo conocimientos que les permite alcanzar metas personales vinculadas al estudio de la música al tiempo que facilita en ellos una oportunidad de desarrollo integral que se manifiesta en el ámbito de lo familiar, la escuela y lo comunitario.

Con mayor precisión y en función del marco epistémico que orienta la práctica colectiva de la música y la socioformación podemos dar cuenta de la vinculación entre la experiencia vivida y las posibilidades teórico-metodológicas que se abren para la formulación de una educación musical con propósitos de desarrollo social (Rodríguez-Reinoso y Luna-Nemecio, 2019).

En este sentido y siendo uno de los propósitos de esta investigación, por cada una de las categorías emergentes presentamos el contraste con otras realidades similares presentes en la bibliografía que ha abordado el tema, para de esta manera enmarcar la propia realidad hondureña que se encausa a la consolidación de una propuesta de educación musical ajustada a sus particularidades y contexto.

\section{Aspecto: Experiencia personal}

\section{Categoría (s) emergente (s): Voluntad personal / motivación social}

Con ello se da cuenta del factor fundamental que ha impulsado la participación de jóvenes en el programa de educación musical de la BSJ-SPS. La decisión personal guiada por su inclinación a la música o por conocimientos previos del instrumento que deseaban tocar, detona la voluntad como fundamento de una acción: el estudiar música. Las personas informantes, jóvenes entre los 15 y 18 años de edad, ponen de manifiesto su querer y con ello sus expectativas de desarrollo personal por medio de la ejecución de un instrumento musical. Porque siempre había llamado la atención la música (Informante 5). Mis motivos fueron porque quería tener más conocimiento sobre el instrumento (Informante 6). Tan solo dos jóvenes expresaron que no venían por voluntad propia sino por decisión de los padres o madres. Mi mamá quiso meterme a estudiar música. No tenía ninguna expectativa al entrar a la BSJ (Informante 1) Por castigo. Mis padres me regañaban por no hacer nada en todo el día y decidieron meterme a la BSJ (Informante 4).

El programa BSJ-SPS funciona como espacio educativo fuera de la escolaridad regular, contrario a la mayoría de los casos del contexto europeo que toman como referencia la propuesta venezolana de El Sistema, los cuales se encuentran vinculados a la escuela (Ehrlin y Gustavsson, 2018; Hospital et al., 2018). De igual modo, esto sucede en Sudáfrica (Roué, 2017) y en algunos países latinoamericanos como Argentina (Valenzuela y Aisenson, 2016). El Sistema, 
http://doi.org/10.15359/ree.26-1.17

http://www.una.ac.cr/educare

educare@una.ac.cr

por su parte, es independiente al recinto escolar (Verhagen et al., 2016). En este sentido, cuando la persona joven manifiesta su voluntad de integrar un espacio educativo distinto al de la escuela demuestra una clara intención en su querer hacer. Cuando está asociado a la escuela, priva la decisión de los y las familiares responsables.

\section{Afirmación positiva de la experiencia vivida}

Con esta categoría emergente se engloba el aspecto vinculado a la influencia que ha tenido en la vida de los actores sociales en lo personal, familiar, escolar y comunitario, la experiencia de formación en la BSJ-SPS. La narrativa testimonial destaca aspectos como el enfrentar relaciones interpersonales, dominar el contacto con el público, alejarse de problemas, lo mismo que en rasgos conductuales como la disciplina y la responsabilidad. Ha cambiado mi vida por completo (Informante 5). A partir de su vivencia en el programa de formación, otras esferas sociales han dado cuenta de dicha influencia. En el colegio me eligen para tocar y cantar y me piden ayuda para la clase de música (Informante 2). Tener a mi familia que me apoya más (Informante 6).

La influencia directa en aspectos de orden personal, lo mismo que en grupos sociales más cercanos como la escuela y la familia, son claramente referidos por investigaciones que han estudiado la relación entre la práctica colectiva de la música y el desarrollo personal-social. Hospital et al. (2018), encontraron resultados satisfactorios al estudiar aspectos del desarrollo personal tales como: el carácter, las competencias, la solidaridad, confianza y pertenencia en jóvenes integrantes del Miami Music Project (MMP), programa inspirado en el modelo venezolano.

Por su parte, la autoestima y la confianza personal fueron los aspectos que señalaron los jóvenes y las jóvenes pertenecientes a un programa de educación musical comunitario en Sudáfrica. No es solamente enseñar a tocar un instrumento, sino que también proporciona una plataforma educativa en la que se desarrollan y perfeccionan los conocimientos proporcionando motivación a través de actividades artísticas estimulantes (Roué, 2017).

\section{Acompañamiento familiar}

Esta categoría da cuenta de manera específica de la conexión e influencia directa surgida en el núcleo familiar de quienes participaron. Los grupos familiares muestran orgullo, agrado y satisfacción por la participación y desarrollo de jóvenes con dedicación musical. Mi familia está orgullosa de mi (Informante 5) Se sienten orgullosos de verme en un escenario, se asombran al ver nuestra institución tocando (Informante 8).

En el trabajo reseñado con anterioridad, D’Alexander e Ilari (2016), el acompañamiento familiar es uno de los más notorios en los hallazgos de la investigación. "[La participación] fue claramente impactando las formas en que los niños y niñas perciben la dinámica familiar y los roles del hogar, así como la transformación social que estaba ocurriendo a través de las

10 Oswaldo Antonio Rodríguez-Reinoso y Josemanuel Luna-Nemecio

Los artículos de la Revista Electrónica Educare del Centro de Investigación y Docencia en Educación de la Universidad Nacional, Costa Rica, se comparten bajo términos de la Licencia Creative Commons: Reconocimiento, No Comercial, Sin Obra Derivada 3.0 Costa Rica. Las autorizaciones adicionales a las aquí delimitadas se pueden obtener en el correo: educare@una.cr 
http://doi.org/10.15359/ree.26-1.17

intersecciones de sus mundos familiares y musicales" (D'Alexander e Ilari, 2016, p. 79). Por su parte, en el planteamiento de Ehrlin y Gustavsson (2018), quienes abordan la percepción de los padres sobre el programa musical inspirado en El Sistema en comunidades migrantes en Suecia, reseñan en sus hallazgos la importancia que adjudican al programa más que todo por el hecho de ayudar a sus hijos e hijas a desarrollar competencias sociales y de interrelación personal más que por el hecho musical mismo.

De esta manera, el núcleo familiar que se vincula a la experiencia de la BSJ-SPS comienza a vivenciar por igual las incidencias positivas del proceso de formación de la persona estudiante, así como también de su paulatino crecimiento en lo personal. La valoración de la familia es parte sustantiva en la visión holística del abordaje pedagógico-didáctico y artístico que se promueve.

\section{Perspectiva del proyecto de vida}

“El proyecto ético de vida consiste en una planeación consciente e intencional que realiza una persona con el fin de dirigir su vida en los diversos campos del desarrollo humano" (Tobón, 2005, p. 10). La dedicación a la música en el futuro mediano y de largo plazo orienta el proyecto ético de vida de las personas participantes de la BSJ-SPS, el cual se complementa con otras aspiraciones en el plano profesional como el hecho de estudiar en la universidad. Lo primero sería graduarme de la BSJ y tener el título de maestro en el instrumento. Segundo, aplicar para una beca en una universidad fuera del país para sacar una ingeniería química o industrial (Informante 6) Ser diseñador gráfico y músico (Informante 3) Pues desearía dedicarme al cien por ciento (Informante 5).

Desde la psicología de la orientación, autores como Valenzuela y Aisenson (2016) encontraron que los proyectos denominados orquesta escuela son "espacios de inserción, contextos facilitadores de construcción de narrativas de vida valoradas y de esta manera facilitan las posibilidades de proyectar el futuro" (p.120). Por su parte, Oriola et al. (2018) quienes analizan el perfil socioemocional de jóvenes que pertenecen a programas orquestales y corales en la Comunidad de Valencia y Cataluña, España, concluyen que es "imprescindible que los adolescentes continúen con la práctica instrumental", facilitando así que "una posible salida laboral, también contribuirá significativamente, ya sea de forma consciente o inconsciente al desarrollo personal de cada músico" (pp. 167-168).

La socioformación como base de un enfoque competencial para la educación musical encuentra en la formulación y ratificación del proyecto ético de vida un aspecto nuclear por tanto constituye el elemento integrador de lo disciplinar (lo musical) y el desarrollo social. Se trata por tanto de una formación en la que las metas de índole técnico-musical o artístico no se separan de las que se relacionan al fomento de una ética (saber ser) consustanciada al saber hacer y saber conocer, la plena conciencia de la necesidad de actuar con sentido incluyente, respetuoso, solidario y totalmente interdependiente de sus pares. 
http://doi.org/10.15359/ree.26-1.17

http://www.una.ac.cr/educare

educare@una.ac.cr

\section{Aspecto: Experiencia pedagógica-didáctica}

\section{Categoría (s) Emergente (s): Énfasis en el aprendizaje y goce personal - Experiencia integral/} holística

Las dos categorías que se encuentran a partir de la narrativa testimonial refieren directamente a la vivencia dentro del programa de formación de la BSJ-SPS desde la perspectiva pedagógica-didáctica. Las personas informantes denotan el aprendizaje como primer aspecto de su experiencia, caracterizándolo como agradable, disfrutado y altamente significativo en términos del conocimiento adquirido, de la relación intersubjetiva entre pares, lo mismo que entre docentes y estudiantes. De allí se comprende la presencia de narrativas en donde la experiencia vivida se concibe como Integral/Holística, en la conjugación del proceso de interacción social de enseñanza-aprendizaje con los aspectos socioemocionales. Me he divertido y he aprendido mucho en estos años y me he esforzado por estudiar (Informante 3) Ha sido divertido, y he aprendido mucho en la parte práctica como teórica (Informante 1) Es una experiencia que no se me olvida a lo largo de estos tres (3) años. He aprendido mucho las actividades que realizamos, vernos cuando hacemos conciertos didácticos y les enseñamos a otros jóvenes cuán importante es la música, arte en nuestra cultura y país (Informante 8).

A este respecto el análisis que realiza Wald (2017) sobre el movimiento de las orquestas juveniles en Argentina, al consultar sobre la valoración que dan a estos espacios de formación las personas participantes, encontró que estos son apreciados por: "[brindar] nuevos conocimientos, socialmente valorados (música académica, 'cultura', 'arte') ... [proporcionar] disfrute (tanto arriba como abajo del escenario)" (p. 65). A juicio de la autora, estos aspectos son "vivenciado como enriquecedor de la propia experiencia" (Wald, 2017, p. 66). Así, el proceso de enseñanza aprendizaje vinculado a factores emocionales positivos, no solo reafirma el propósito mismo de la enseñanza desde la institucionalidad, sino que perfila percepciones de las personas participantes altamente significativas con aquello que se aprende.

\section{Propósitos disciplinares y propósitos del desarrollo social}

En estas dos categorías, o más bien una categoría compartida/ampliada, se encierran las percepciones de quienes participaron en cuanto a los aspectos más significativos del programa de formación musical de la BSJ-SPS, explorando con ello la mirada hacia la institucionalidad. Las personas informantes son claras al connotar la enseñanza de la música o la enseñanza del instrumento como el aspecto más significativo que observan del programa de formación, lo que equivaldría a propósitos disciplinares. Sin embargo, tal percepción viene acompañada de una mirada sobre otros aspectos extra musicales como valores, preservación del ambiente y crecimiento personal, lo cuales se encierran dentro de los propósitos del desarrollo social. Enseñar música y hacer que los estudiantes logren llegar más alto (Informante 1) A enseñarnos a

Oswaldo Antonio Rodríguez-Reinoso y Josemanuel Luna-Nemecio

Los artículos de la Revista Electrónica Educare del Centro de Investigación y Docencia en Educación de la Universidad Nacional, Costa Rica, se comparten bajo términos de la Licencia Creative Commons: Reconocimiento, № Comercial, Sin Obra Derivada 3.0 Costa Rica. Las autorizaciones adicionales a las aquí delimitadas se pueden obtener en el correo: educare@una.cr 
http://doi.org/10.15359/ree.26-1.17

ser buenos músicos, a poder ser mejores en la técnica con nuestro instrumento, pero más importante nos enseñan valores, a ser responsables, respetuosos, puntales, honestos (Informante 4) La clase de coro, la considero muy importante. Los ensambles son muy importantes porque ayuda al trabajo en equipo como agrupación (Informante 5) Que cuidemos el medio ambiente, integridad, respeto, puntualidad, responsabilidad, ayudarnos a otros (Informante 8)

Es en este punto donde los propósitos de la presente investigación encuentran uno de sus nodos neurálgicos: la educación musical vista desde la socioformación (Tobón, 2015) y orientada al desarrollo social sostenible (Luna-Nemecio, 2020) la cual requiere del diseño curricular, competencias y programas que articulen una nueva visión de la educación musical. Para ello, el desarrollo social sostenible como concepción epistémica sirve de sustento a la emergencia de "mecanismos para el incremento en la calidad de vida de las personas, ... preservación de los procesos ecológicos, biodiversidad, la equidad de género" (Juárez-Hernández et al., 2019, p. 57).

En este sentido, la alternativa de una educación musical desde las práctica colectiva de la música como espacios socioformativos es cónsona con el planteamiento del desarrollo social sostenible al propiciar espacios de enseñanza-aprendizaje orientados al desarrollo competencial desde el trabajo en colectivo, a la mejora de la calidad de vida, el fortalecimiento de una ética desde la cual se asume como criterio fundamental la preservación de la vida tanto el plano ecológico como en el plano político por medio de una praxis educativa inclusiva, de calidad, impulsora de un proyecto ético de vida y firme barrera ante los flagelos sociales de la delincuencia, la prostitución, las drogas, la violencia física y psicológica, la exclusión.

\section{Aceptación de la metodología-reconocimiento del rol docente}

Estas dos siguientes categorías se comprenden a partir de la idea que tienen las personas informantes sobre el planteamiento metodológico del programa de formación en la BSJ-SPS y la relación social docente-estudiante. Al respecto puede evidenciarse en la narrativa testimonial, voces que valoran de manera positiva el abordaje pedagógico-didáctico: Que es buena y unida, el contenido lo enseñan de una manera buena y no tan aburrida como pensé que sería (Informante 4) El trabajo de los docentes me parece excelente, creo que la metodología y el aprendizaje están muy bien (Informante 7) Es una metodología que nos lleva a un estudio individual y a veces a partes seccionales (Informante 6). Sin embargo, para las informantes 1 y 2 su percepción difiere del resto ya que para el momento de levantar el estudio no cuentan con la guía del maestro de instrumento desde hace mucho tiempo, razón por la cual su percepción es negativa: Pues la verdad no tenemos maestro y muchas veces tenemos que pedirle ayuda al Profe. A o al Profe. $B$, el contenido de las clases es muy poco (por la misma razón) al igual que la metodología (a excepción de coro) que el aprendizaje ha sido muy bueno y mejorado (Informante 1). Como no tenemos maestro, asíque no opino nada (Informante 2). Sobre este aspecto la institución reconoce sus debilidades estructurales y es consciente que esto puede debilitar a la comunidad de aprendizaje. 
http://doi.org/10.15359/ree.26-1.17

http://www.una.ac.cr/educare

educare@una.ac.cr

En cuanto al relacionamiento con el personal docente se encuentran testimonios que por igual ratifican la metodología de trabajo, pero vinculada a sus experiencias más directas con el rol docente, a quien atribuyen características relacionadas al ámbito de la orientación, guía, etc. Considero al maestro A el más enfocado en transmitir sus conocimientos porque en su clase ponemos en práctica lo aprendido en clase de teoría y clase de instrumento (Informante 5) - Mi maestro $C$ que me ayudó con las escalas, los ejercicios, su método de enseñar es muy bueno, las clases en cuartetos, a veces trabajamos seccional (Informante 8).

Sobre este aspecto conviene mencionar que la efectividad del abordaje pedagógicodidáctico es fundamental en la concepción de un ambiente social propicio no solo para el aprendizaje disciplinar sino para el verdadero desarrollo personal-social. Oriola et al. (2018). Así, los diferentes grados de interés en el aprendizaje a partir de las diversas formas de estimulación didáctica que se ofrecen en la práctica orquestal, genera una vinculación mayor de las personas participantes en el aprendizaje (Piscazzi, 2015).

\section{Aspecto: Experiencia artística}

\section{Categoría Emergente: Sentido de autorrealización}

En esta última categoría, perteneciente al ámbito de las experiencias de tipo artísticas vivenciadas en el programa de formación BSJ-SPS, se busca comprender la significatividad que tiene el hecho artístico, la participación en conciertos, recitales y muestras musicales, para los informantes.

La narrativa testimonial muestra el sentido que tiene el momento del concierto como instancia concomitante al plano pedagógico-didáctico, cuya significación se remite a la expresión de las subjetividades en el acto creador. Ha significado mucho poder tocar con la banda. Es como una recompensa para mí, con el esfuerzo que día a día estudiamos para prepararnos para los conciertos (Informante 4) Es una experiencia que te llena de adrenalina, los pelos de punta, nervios de acero, y pensar cada segundo de lo que haces, sabiendo que te encanta y te llena de emoción y más amor hacia la música, sabiendo que te has preparado para ese momento (Informante 6) Pues me siento con mucha alegría por llegar a donde estoy porque sé que he llegado a lejos. Siento la música cuando la ejecuto y no decir no puedo hacerlo, no puedo tocarlo se ha significado mucho para mí (Informante 8) Los conciertos y recitales ayudan al desenvolvimiento persona y al tocar en los escenarios siento que expreso con el instrumento lo que no se puede expresar con palabras (Informante 5).

Dos estudios que atienden en sus propósitos el aspecto artístico que implica la práctica colectiva de la música, revelan la pertinencia que tiene el reflexionar en torno a un componente artístico consustanciado en el académico. Wald (2017) encontró en su análisis de programas orquestales juveniles, que las personas participantes reforzaban la idea de que esta actividad (la orquesta, el concierto) les permitía mostrar o demostrar "a través de la acción y no de la 
http://doi.org/10.15359/ree.26-1.17

palabra que no son aquello que muchos creen que son porque viven en una villa (comunidad) de emergencia" (p. 66). Salas Rivera (2018), por su parte, concluye que la generación de espacios de aprendizaje musical y artístico, permite a la niñez y juventud cultivar sentido de pertenencia y autoestima, entre otros valores al considerarse"representantes de su comunidad y embajadores musicales de la región" (p. 45).

\section{Conclusiones}

La experiencia personal, pedagógico-didáctica y artística vivenciada por estudiantes del programa de la BSJ-SPS se ha manifestado a partir de una narrativa testimonial que muestra a estudiantes de música que se reconocen plenamente como actores sociales inmersos en un proceso de enseñanza-aprendizaje en el que se conjugan sus aspiraciones por convertirse en músicos profesionales junto a la interacción con sus pares desde un dispositivo pedagógicodidáctico queles brinda la oportunidad de desarrollarse personalmente, incidiendo directamente en el resto de sus espacios sociales a los que pertenecen.

La propuesta de una educación musical con propósitos de desarrollo social en el contexto hondureño encuentra posibilidades de estructurarse plenamente como un planteamiento propio, contextualizado, teniendo por base elementos teóricos la socioformación y el desarrollo social sostenible, lo que implica un reto en su incorporación a los diseños pedagógicosdidácticos de una nueva concepción de la educación musical: la que se concibe como mediación y finalidad al mismo tiempo. Esto, claramente zanja la distancia con el esquema tradicional de la educación musical decimonónica.

Visto de este modo, el fortalecimiento de las instituciones responsables de educación musical es uno de los principales elementos a considerar a la luz de los hallazgos obtenidos. Si bien la evidencia empírica ha dado cuenta de la pertinencia de un planteamiento pedagógicodidáctico que sirve de mediación para la restitución de equilibrios sociales necesarios para una nueva sociedad en medio de la convulsiva posmodernidad, no menos cierta es la necesidad de formalizar teórica y metodológicamente estas iniciativas de formación musical desde la práctica colectiva de la música.

Los tres aspectos de esta experiencia formativa musical de la BSJ-SPS deben servir de orientación a la formalización del propio planteamiento de una educación musical con propósitos de desarrollo social. Tanto lo personal, lo pedagógico-didáctico, como lo artístico configuran una triada que se articula desde la socioformación, exigiendo así una mayor claridad en cuanto sus alcances y limitaciones en el plano educativo.

En este orden de ideas es preciso entonces poner en juego un verdadero enfoque competencial. Las competencias para una educación musical no son ajenas a los espacios no formales de educación musical. Así, la formalidad en la concepción, desarrollo y valoración del 
http://doi.org/10.15359/ree.26-1.17

http://www.una.ac.cr/educare

educare@una.ac.cr

dispositivo pedagógico-didáctico debe tener por fuente la evidencia empírica que tanto en este caso como los observados a través de las investigaciones aquí citadas, ratifican la noción de competencias: un actuar y desempeñarse con idoneidad ante una situación problema real que exige la aplicación de los saberes esenciales.

Del mismo modo, los aspectos que vinculan el desarrollo social deben ser estimados en esa formalización del dispositivo pedagógico-didáctico para evitar quedar como simples declaraciones. Esto exige la formulación de indicadores más precisos que se consustancien con el propio marco que encierra la categoría desarrollo social sostenible. Por tanto, la configuración de un modelo competencial para una educación musical debe estar atravesado transversalmente por lo principios del desarrollo social de manera que haga posible una más nítida observación de los logros que se atribuyen a la educación musical con propósitos de desarrollo social.

Para la educación musical hondureña, el caso de la BSJ-SPS representa un importante punto de partida para el desarrollo de nuevas formulaciones que vehiculen con más fuerza la acción social desde las artes, en este caso específico desde la música. Esto pasa por una necesaria acción política que asuma decisiones muy concretas basadas en la evidencia empírica como vía directa a construir nuevos espacios educativos y artísticos altamente consustanciados con las realidades sociales para de esta manera brindar sólidas oportunidades a la infancia y a la juventud hondureña.

\section{Declaración de Material complementario}

Este artículo tiene disponible, como material complementario:

-La versión preprint del artículo en https://doi.org/10.5281/zenodo.4891659

-El instrumento de entrevista. Para acceder a esta información visite:

https://doi.org/10.1539/ree.26-1.17

\section{Referencias}

Alemán, X., Duryea, S., Guerra, N. G., McEwan, P. J., Muñoz, R., Stampini, M. y Williamson, A. A. (2016). Los efectos de la formación musical en el desarrollo infantil: Una prueba aleatoria de El Sistema en Venezuela. BID. https://bit.ly/36JKVwL

Baker, G. (2018). El sistema "The Venezuelan Musical Miracle": The construction of a global myth. Latin American Music Review, 39(2), 160-193 https://doi.org/10.7560/LAMR39202

Cerda, H. (1993). Los elementos de la investigación. Cómo reconocerlos, diseñarlos y construirlos. Abya Yala. 
http://doi.org/10.15359/ree.26-1.17

http://www.una.ac.cr/educare educare@una.ac.cr

Corbetta, P. (2007). Metodología y técnicas de investigación social (2. a ed.). McGraw-Hill.

D’Alexander, C. e Ilari, B. (2016). La transformación social de dos estudiantes en un programa Orquestal inspirado en el El Sistema. Revista Internacional de Educación Musical, (4), 75-84. https://doi.org/10.12967/RIEM-2016-4-p075-084

Ehrlin, A. y Gustavsson, H.-O. (2018). El Sistema as an opportunity for collaboration between school and home - parents' perspectives on an eEl sistema-inspired activity. International Journal of Learning, Teaching and Education Research, 17(8), 36-55.https://doi.org/10.26803/ ijlter.17.8.3

Escribal, F. L. (2017). Orquestas infanto-juveniles suramericanas en perspectiva de derechos culturales. Foro de Educación Musical, Artes y Pedagogía, 2(2), 107-127 http://www. revistaforo.com.ar/ojs/index.php/rf/article/view/31

Hospital, M. M., Morris, S. L., Wagner, E. F. y Wales, E. (2018). Music education as a path to positive youth development: An El sistema-inspired program. Journal of Youth Development, 13(4), 149-163. https://doi.org/10.5195/jyd.2018.572

Juárez-Hernández, L. G., Tobón, S., Salas-Razo, G., Jerónimo-Cano, A. E. y Martínez-Valdés, M. (2019). Desarrollo sostenible: Educación y sociedad. Revista electrónic@ de Medio Ambiente, 20(1), 54-72. https://bit.ly/30xiKgw

López, V. (24 de febrero, 2021). Tocar y Luchar (Sistema de Orquestas Juveniles e Infantiles de Venezuela) [Documental]. YouTube. https://www.youtube.com/watch?v=1CLUiEjZ52w

López-Vázquez, R. y Veytia-Bucheli, M. G. (2019) La práctica pedagógica socioformativa como estrategia que favorece el desarrollo social sostenible. Ecociencie International Journal, 1(1), 52-62. https://doi.org/10.35766/je19118

Luna Nemecio, J. M. (2020). Para pensar el desarrollo social sostenible: Múltiples enfoques, un mismo objetivo. Kresearch/ Religación. Centro de Investigaciones en Ciencias Sociales y Humanidades desde América Latina. https://doi.org/10.35766/dss20

Mejía Navarrete, J. (2011). Problemas centrales del análisis de datos cualitativos. Revista Latinoamericana de Metodología de la Investigación Social, 1(1), 47-60. http://relmis.com. ar/ojs/index.php/relmis/article/view/43

Oriola, S., Gustems, J. y Filella G. (2018). Las bandas y corales como recurso para el desarrollo integral de los adolescentes. Revista electrónica Complutense de Investigación en Educación Musical, 15, 153-173. https://doi.org/10.5209/RECIEM.58813

Piscazzi, A. (2015). La sperimentazione de "El sistema" di Antonio José Abreu nei nuclei musicali pugliesi. Reladei, 4(2), 163-180. https://revistas.usc.gal/index.php/reladei/article/ view/4888 
http://doi.org/10.15359/ree.26-1.17

http://www.una.ac.cr/educare

educare@una.ac.cr

Rodríguez, O. (2019). La educación musical y el desarrollo social. Innovare: Revista De Ciencia Y Tecnología, 8(2), 124-127. https://doi.org/10.5377/innovare.v8i2.9089

Rodríguez-Reinoso, O. A. y Luna-Nemecio, J. L. (2019). Educación musical para el desarrollo sostenible: Una revisión documental. Revista da Abem, 27(43), 132-149. https://www. researchgate.net/publication/337461720_Educacion_musical_para_el_desarrollo sostenible una revision documental

Roué, N. Y. (2017). Exploring music education as agent of social development in Mamelodi, a community in South Africa [Tesis de maestría]. University of Pretoria. https://bit.ly/3d5Ft8w

Salas Rivera, I. L. (2018). La práctica musical como espacio de inclusión social infantil: Experiencias de Portal Norteño Music Perú en Huacho, Huaura. Antec: Revista Peruana de Investigación Musical, 2(1), 31-48. http://revistas.unm.edu.pe/index.php/Antec/article/view/29

Strauss, A. y Corbin, J. (2002). Bases de la investigación cualitativa. Técnicas y procedimientos para desarrollar la teoría fundamentada. Editorial Universidad de Antioquia.

Tobón, S. (2005). Formación basada en competencias. Pensamiento complejo, diseño curricular y didáctica. Ecoediciones.

Tobón, S. (2015). La socioformación: Avances y retos en la sociedad del conocimiento. En COMIE (Ed.). Conferencias magistrales del Congreso Nacional de Investigación Educativa (pp.179234) COMIE. https://www.researchgate.net/publication/312563616 Socioformacion avances y retos en la sociedad del conocimiento Conferencia en el Comie Mexico 2015

Valenzuela, V. y Aisenson, G. (2016). Jóvenes en orquesta escuela: Construcción de identidad y proyectos de futuro. Anuario de Investigaciones, 23,115-121 http://ppct.caicyt.gov.ar/ index.php/anuinv/article/view/9182

Verhagen, F., Panigada, L. y Morales R. (2016). El sistema nacional de orquestas y coros juveniles e infantiles de Venezuela: Un modelo pedagógico de inclusión social a través de la excelencia musical. Revista Internacional de Educación Musical, (4), 35-46. https://doi.org/10.12967/ RIEM-2016-4-p035-046

Wald, G. (2017). Orquestas juveniles con fines de inclusión social. De identidades, subjetividades y transformación social. Foro de Educación Musical, Artes y Pedagogía, 2(2), 59-81 http:// www.revistaforo.com.ar/ojs/index.php/rf/article/view/27/64 